\title{
Metacognitive Instruction and Interactional Feedback in a Computer-Mediated Environment
}

\author{
Nicole Ziegler, Kara Moranski, George Smith, E Huy Phung
}

Multiple theoretical frameworks support the notion of interactional feedback as facilitative of second language (L2) development. However, research demonstrates that learners often avoid providing feedback during peer collaborative work, thus failing to take advantage of key opportunities for language learning and development. Recent studies have examined how metacognitive instruction (MI) may be used to explicitly train learners in the provision of interactional feedback, with results showing increased instances of feedback (Fujii et al., 2016) and improved L2 outcomes (e.g., Sato \& Loewen, 2018; Sippel, 2019). Building on this work, this exploratory study investigated the effects of MI on intermediate L2 English learners' $(n=26)$ provision of interactional features in synchronous computer-mediated communication. Using a pretest-treatment-posttest design, all learners completed three decision-consensus tasks, with learners in the treatment group receiving direct instruction on the benefits of interaction via an instructional video, a practice task, and subsequent whole-class debriefing. The control group completed the tasks without MI. Results demonstrate that learners' provision of interactional feedback and language-related episodes increased following MI, with qualitative measures indicating learners had positive perceptions of the training and improved awareness of the potential benefits of interactional feedback in computer-mediated communication.

De multiples approches théoriques soutiennent la notion de rétroaction interactionnelle comme facilitateur du développement d'une langue seconde (L2). Cependant, les recherches démontrent que les apprenants évitent souvent de présenter une rétroaction pendant le travail collaboratif entre pairs, ne profitant ainsi pas des principales possibilités d'apprentissage et de développement des langues. Des études récentes ont examiné comment l'enseignement métacognitif (EM) peut être utilisé pour former explicitement les apprenants à la rétroaction interactionnelle, les résultats montrant une augmentation des cas de rétroaction (Fujii et al., 2016) et une amélioration des résultats en L2 (par exemple, Sato $\mathcal{E}$ Loewen, 2018; Sippel, 2019). S'appuyant sur ces travaux, cette étude exploratoire a examiné les effets de l'EM sur l'offre de fonctions interactionnelles dans la communication synchrone par ordinateur aux apprenants d'anglais de niveau intermédiaire L2 $(n=26)$. En utilisant un modèle de pré-traitement-post-test, tous les apprenants ont accompli trois tâches de consensus décisionnel, les apprenants $d u$ groupe de traitement recevant des consignes directes sur les avantages de l'interaction via une vidéo pédagogique, une tâche de pratique et un compterendu ultérieur pour toute la classe. Le groupe de contrôle a effectué les tâches 
sans EM. Les résultats montrent que l'apport d'une rétroaction interactionnelle et d'épisodes liés à la langue par les apprenants a augmenté après l'EM, avec des mesures qualitatives indiquant que les apprenants avaient des perceptions positives de la formation et une meilleure sensibilisation aux avantages potentiels de la rétroaction interactionnelle dans la communication par ordinateur.

Key Words: interaction, synchronous computer-mediated communication, corrective feedback, language-related episodes, metacognitive instruction

The importance of conversational interaction for second language (L2) development is well-documented, with myriad empirical studies and syntheses providing evidence of its benefits (see Keck et al., 2006; Mackey \& Goo, 2007; Ziegler, 2016 for reviews). Interaction offers learners opportunities to negotiate for meaning as well as to give and receive feedback in response to linguistic or communicative problems; this potentially directs their attention to differences in both erroneous production and features of the L2 (Mackey, 2012). These opportunities for noticing may encourage learners to repair misunderstandings by producing modified output, thereby supporting deeper levels of processing and facilitating L2 development (Swain, 1985, 1995, 1998, 2005; Swain \& Lapkin, 1995). In other words, these interactional modifications support L2 learning through the "connection of input, internal learner capacities, particularly selective attention, and output in productive ways" (Long, 1996, pp. 451-452). Despite these potential benefits, learners may not recognize or take advantage of developmental opportunities during peer interaction. For example, findings demonstrate that learners may fail to respond to errors, to seek clarification in response to a miscommunication, or to engage with their interlocutors (e.g., Fujii \& Mackey, 2009; Sato, 2013). Seeking to support learners in becoming more effective interlocutors, studies have explored how direct instruction on the benefits of interaction may influence learners' engagement and production (e.g., Fujii \& Mackey, 2009; Sato, 2013). Results are promising, with findings indicating increased provision of interactional features, such as corrective feedback, as well as improved developmental outcomes (e.g., Fujii et al., 2016; Sato, 2013; Sato \& Lyster, 2012; Sippel, 2019). Extending these investigations from traditional face-to-face (FTF) classrooms to technology-mediated environments, this research explores how metacognitive instruction (MI) impacts learners' production of interactional features during synchronous computer-mediated communication (SCMC). 


\section{Interaction in Computer-Mediated Contexts}

Interaction in computer-mediated contexts has been shown to produce similar L2 interactional features as in traditional, FTF environments, including negotiation, corrective feedback, and language-related episodes (LREs, e.g., Pellettieri, 2000; Plonsky \& Ziegler, 2016; Zeng, 2017; Ziegler, 2016). LREs, operationalized as "any part of a dialogue where the students talk about the language they are producing, question their language use, or correct themselves or others" (Swain \& Lapkin, 1998, p. 326), provide important opportunities for learners to resolve linguistic miscommunications or problems, co-construct their linguistic knowledge, and support subsequent L2 development and performance (Swain, 1998; Swain \& Lapkin, 1998).

Previous research has also identified potential advantages for interaction in technology-mediated environments. For instance, the visual representation of L2 production provided by text chat allows learners to review their interactions in real time, potentially enhancing the saliency of the input and supporting learners' attention to form (e.g., Smith, 2004, 2005), while also supporting self-monitoring and self-correction (Lee, 2009; Sauro \& Smith, 2010). Additionally, text chat can offer longer processing times when compared to FTF interaction (Pellettieri, 2000), providing learners with greater opportunities for noticing target language features (Payne \& Whitney, 2002; Salaberry, 2000; Smith, 2004). Computer-mediated communication may also encourage greater risk-taking in the L2 and increased or more equitable participation from less-active learners (Chun, 1994; Meunier, 1998; Warschauer, 1996), with recent findings demonstrating that learners produced more LREs in SCMC than learners in FTF interactions (Zeng, 2017). Taken together, these findings demonstrate how the unique affordances of technology-mediated environments may facilitate the benefits associated with interaction in traditional FTF environments.

\section{Peer Feedback}

Interlocutor characteristics have been identified as an important influencing factor on the amount and type of feedback produced during L2 interactions, with findings suggesting interesting patterns for learner-learner interaction (Mackey et al., 2003; Mackey \& Oliver, 2002; Sato \& Lyster, 2007). For example, Mackey et al. (2003) found that even though adult learners provided less feedback to other learners (as compared to learner-native-speaker dyads), learners provided one another with more opportunities for modified output. The interlocutor may also affect the type of feedback provided during interaction, as learners have been found to produce more elicitation types of feedback than native-speaker interlocutors (Sato \& Lyster, 2007).

However, research also indicates that social factors or concerns regarding their own L2 proficiency may influence how much feedback learners produce 
during peer interaction (Philp et al., 2010; Sato \& Ballinger, 2012). Learners' shared cultural backgrounds may also account for low rates of negotiation and feedback, as learners may find feedback to be a face-threatening or socially inappropriate act (Fujii \& Mackey, 2009; Sato \& Lyster, 2007). Hesitation to negotiate and provide feedback is not limited to learners with shared cultural backgrounds and beliefs; learners of diverse backgrounds may also fail to provide feedback out of concern that it may be found inappropriate by their peer interlocutors (Mackey et al., 2003).

The quality of peer feedback, as well as its recognition and reception by peer interlocutors, may also differ from the feedback provided in learnernative speaker interactions. For example, learner-provided feedback may be unrelated to instructional tasks or targets, or it may be prioritized for task completion rather than directed towards target-language production (Toth et al., 2013). Learners may also fail to understand feedback (Loschky \& Bley-Vronman, 1990; Toth et al., 2013) or to recognize that feedback is being provided in response to their erroneous production (Adams et al., 2011). Finally, Foster and Ohta (2005) point out that negotiation may be unnatural for learners, as "'negotiation for meaning' is not a strategy that language learners are predisposed to employ when they encounter gaps in their understanding" (Foster 1998, p. 1).

\section{Metacognitive Instruction}

A promising technique for supporting learners' active engagement in peer interaction is MI. Training in metacognition (i.e., reflecting on one's own cognition) allows learners to "plan, monitor, and control their own mental processes" (McGuire, 2015, p. 13). MI for interactional feedback seeks to direct learners' attention to conversational moves that highlight gaps between what a learner has produced and the L2 forms needed for communication and comprehension. For example, previous research has examined how explicit training in the provision of corrective feedback and/or the initiation and resolution of LREs may deepen learners' understanding of how interactional features and corrective feedback support L2 development (Sato \& Lyster, 2012; Fujii et al., 2016). Such directed attention increases the saliency of input and corrective feedback, promoting deeper processing and subsequent retention (Leow, 2015, 2018).

Several studies have shown MI to be effective for enhancing learnerlearner feedback and facilitating interactional behaviours associated with L2 learning. For example, Fujii and Mackey (2009) trained Japanese first language (L1) English foreign language (EFL) learners on the importance of interaction, providing instruction on various techniques for giving corrective feedback. Following this instruction learners had greater gains in the provision of feedback and overall task performance when compared to those who had not received instruction. Similarly, Sato (2013) found that following 
MI, EFL learners were more willing to provide feedback to one another and also reported increased trust in their peers as learning resources. The results of Fujii et al. (2016) demonstrated that Japanese EFL learners' provision of corrective feedback and LREs increased after MI. More recently, Dao (2020) taught interaction strategies to Vietnamese learners of English. Findings indicated that learners who received instruction generated more idea units, showed more positive emotions towards interaction, and had greater levels of participation in collaborative linguistic dialogue than learners who did not receive instruction.

Research also suggests that metacognitive training may facilitate L2 development. For example, the results of Sato and Lyster (2012) showed that learners who had been trained to provide corrective feedback on their interlocutors' errors outperformed learners who had not received training; gains in L2 accuracy from the MI group outpaced those of the control group. Similarly, Sippel (2019) found increased vocabulary acquisition for L2 German learners who had received training in corrective feedback as compared to learners in a control group. However, the impact of MI may be moderated by task type, L2 target structures, or other contextual factors (Sato \& Loewen, 2018).

Although the existing body of work supports the benefits of MI for improving peer interaction, the modest number of existing studies and their limited contexts currently limit broader conclusions regarding the efficacy of MI for interactional feedback. Many of the studies to date have focused on Japanese L1 learners studying English in an EFL context (e.g., Fujii et al., 2016; Sato, 2013; Sato \& Lyster, 2012). Additionally, MI has been primarily investigated in a traditional FTF classroom environment. In this exploratory study, we thus sought to expand research examining MI in terms of both learner population and instructional context by investigating the effects of MI on English as a second language (ESL) learners' provision of interactional features in an SCMC environment.

\section{The Current Research}

Building upon previous research, this study seeks to explore how metacognitive training impacts learners' provision of interactional features by examining the following research questions:

1. How does metacognitive training impact interactional features in SCMC?

2. What are learners' perceptions of metacognitive training in SCMC?

3. What are learners' perceptions of interaction in SCMC following metacognitive training? 


\section{Method}

\section{Participants}

Twenty-six ESL learners were randomly separated into 13 dyads to complete the tasks for this study. All participants belonged to two intact, intermediatelevel academic listening and speaking classes at a mid-sized university in the United States. Participants included 17 females and 9 males who ranged in age from 19 to 75 years old $(M=22.9, S D=6.41)$. Their L1s included Japanese $(n=12)$, Korean $(n=6)$, Mandarin Chinese $(n=5)$, Cantonese $(n=1)$, Thai $(n=1)$, and Turkish $(n=1)$. Participants had spent an average of 11.5 years studying English in foreign language contexts $(S D=5.10)$. All had lived in the United States for less than a year at the time of data collection $(M=0.25$, $S D=0.64)$.

\section{Design}

Following Fujii et al. (2016), the study adopted a quasi-experimental design of pretest, treatment, and posttest, with interactional tasks serving as the pre- and posttest measures. Each intact class was randomly assigned as the treatment ( $n=8$ dyads) or control $(n=5$ dyads) group. All dyads carried out the same pre- and post-tasks in a text-based SCMC environment. These tasks were counterbalanced across groups in order to control for any effects related to task content and design. The experimental group viewed a threeminute video on how to give metacognitive feedback in interaction and had a whole-class debriefing session, including a practice task. The control group completed the tasks, including the practice task, without receiving any MI. All participants completed an exit survey following the post-task. Figure 1 (adapted from Fujii et al., 2016) illustrates the design of the current research.

Figure 1

Instructional Treatment

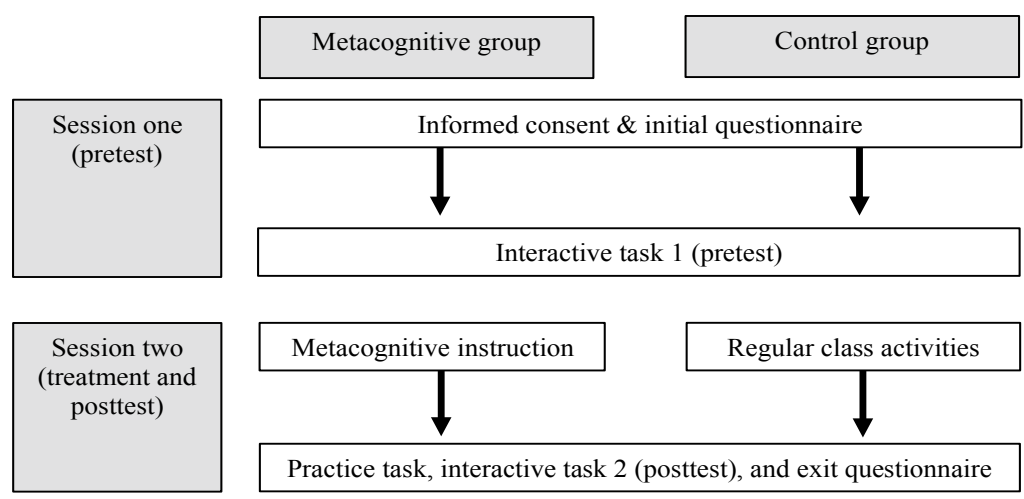




\section{Materials}

\section{Interactive Tasks}

Three versions of a hybrid jigsaw/decision-making task were adapted from previous task-based research for use in the study (Smith \& Ziegler, 2016; Yanguas, 2012). Participants were given 10 minutes to complete each task, all of which aligned with Pica et al.'s (1993) definition of a decision-making task. Each version was based around a central decision-making theme. Version A tasked the participants with selecting a limited set of items to take on a competitive journey across Latin America, while Version B was an adaptation of the heart transplant task (e.g., Pica \& Doughty, 1985), but focused on the topic of immigration. If participants completed a task early, they were encouraged to continue interacting and to create a list ranking the candidates. Version C, which was used as the practice task, was similar to Version B but tasked participants to select among eight candidates for a heart transplant.

\section{Metacognitive Instruction}

The treatment group participated in a 30-minute instructional workshop delivered FTF by the third author of the study (see Figure 1). The workshop was based around a short animated video on peer corrective feedback (Ziegler \& Moranski, 2018). This video, based on MI videos for active (flipped) learning models (Moranski \& Henery, 2017), described the benefits of interactional peer feedback, explained different methods of giving feedback, provided examples of feedback in action, and promoted collaborative discussion about the target language. The methods of feedback were presented as being part of a continuum ranging from indirect feedback (clarification requests, confirmation checks, LREs, and recasts) to direct feedback (explicit correction). The MI session began with learners viewing this video as a group, and researchers then encouraged participants to ask any clarification questions. They were then given a set of five review questions to discuss in pairs for approximately five minutes: (a) Why is corrective feedback good?

(b) How do we do corrective feedback? (c) How can corrective feedback help you? (d) Did anything surprise you about the video? and (e) How do you feel about giving this kind of feedback? The class then debriefed by sharing their answers to these questions with the researchers and the whole group. Finally, learners engaged in a guided practice task (Task Version C). During the practice task, the researchers circulated around the room to answer any clarification questions and encourage the participants to try using feedback. The practice task was immediately followed by the post-task. 


\section{Exit Survey}

Adapted from Baralt (2010) and Fujii et al. (2016), the exit survey was administered following the completion of the post-task using the Qualtrics survey platform. Two versions of the survey were administered. The version for the control group contained four close-ended and two open-ended items regarding general perceptions of the interactive tasks. The version for the treatment group contained 18 close-ended and three open-ended items. All items were designed to elicit perceptions regarding the general efficacy of interactional feedback for L2 learning, opinions on the training workshop and video, feedback on how the training influenced noticing (e.g., of feedback, errors, language), and perceptions of the tasks used in the study. The surveys took approximately 10-15 minutes to complete.

\section{Procedure}

The study covered two 75-minute class sessions in the same week, one day apart. On Day 1, the participants filled out informed consent forms, completed the background questionnaire, and carried out the pre-task. The research activities lasted approximately 45 minutes, with the remaining time filled by the regular classroom activities. On Day 2, the treatment group participated in the instructional workshop and practice task, carried out the post-task, and filled out the exit survey. The second session lasted approximately 75 minutes. The control group carried out the practice task, post-task, and completed the exit survey, which took approximately 35 minutes. All instructional tasks were carried out in a computer laboratory at the university using an online conferencing tool.

\section{Analysis}

Learners' interactions were coded according to the following guidelines based on Pica (1994). First, the total number of errors made by each learner were counted (lexical, grammatical, and orthographic errors were combined into the category "error") and divided by the total number of utterances produced. That number was subtracted from one to generate an accuracy rate. Subsequently, negotiation sequences were extracted from the chat scripts for coding by identifying instances of interactional feedback given following nontarget-like production, which has also been called "negative feedback" (Oliver \& Mackey, 2003). Five coding categories were adopted to classify feedback type: recasts, clarification requests, confirmation checks, comprehension checks, and explicit feedback. Although learners provided both indirect and direct forms of recasts, such as the examples in Table 1, all recasts were included in the same category for type of feedback. 
Table 1

Definitions of Interactional Feedback

\begin{tabular}{|c|c|c|}
\hline Code & Definition & Example \\
\hline Clarification request & $\begin{array}{l}\text { Phrases indicating missed or partial } \\
\text { understanding }\end{array}$ & $\begin{array}{l}\text { "What? Sorry? Huh? Could } \\
\text { you repeat that?" }\end{array}$ \\
\hline Confirmation check & $\begin{array}{l}\text { Phrases indicating partial } \\
\text { understanding that contain the } \\
\text { trouble source and optionally- } \\
\text { attached question words }\end{array}$ & "Runned? What's runned?" \\
\hline Comprehension check & $\begin{array}{l}\text { Phrases used to "anticipate } \\
\text { and prevent a breakdown in } \\
\text { communication"1 }\end{array}$ & $\begin{array}{l}\text { "Do you understand? Did } \\
\text { you get it?" }\end{array}$ \\
\hline Recast & $\begin{array}{l}\text { "Reformulation of all or part of } \\
\text { utterance, minus the error"2; } \\
\text { optionally contains phrases such as } \\
\text { "You mean" to hedge correction }\end{array}$ & "Ran." "You mean ran." \\
\hline Explicit feedback & Explicit provision of the correct form & $\begin{array}{l}\text { "The past tense of 'run' is } \\
\text { 'ran', not 'runned'." }\end{array}$ \\
\hline
\end{tabular}

${ }^{1}$ Long (1983, p. 136)

²yster \& Ranta (1997, p. 46)

Each instance of feedback was then coded for modified output according to guidelines set by Gurzynski-Weiss and Baralt (2015). It was first determined whether an opportunity for modified output had been provided (i.e., whether there was a sufficient pause in conversation or if the interlocutor immediately continued their turn following the provision of feedback). Modified output was then coded binarily. Lastly, the data were coded for LREs following Swain and Lapkin's (1998) definition of an LRE - "any part of a dialogue in which students talk about the language that they are producing, question their language use, or correct themselves or others" (p. 326). The LREs were separated into lexical and grammatical categories for coding. LREs were considered lexical in nature if learners discussed the meaning of an L2 word or phrase independently or in combination with conversations about L2 orthography, pronunciation, and word choice. Grammatical LREs were defined as discussions about the grammatical features produced by students. An example of a lexical LRE from the current data is illustrated below.

A: and then, I think water is also important, so how about water filter and purifier? 
B: compass \& tent is $45 \$$

anything else?

what is water filter and purifier?

A: make dirty water to clean water! (Maybe!)

B: I got it!

Following previous research, learners' LREs were also coded as "resolved" or "unresolved" (e.g., Ahmadian \& Tajabadi, 2020; Kim \& McDonough, 2008; Payant \& Kim, 2019). LREs were considered resolved if the lexical or grammatical issue was correctly addressed through learnerlearner collaboration or self-correction. Unresolved was defined as cases where the learners could not solve the problem, did not know the answer to the question, or when the issue was ultimately ignored. The data were initially coded by the third and fourth authors of the study, who resolved any disagreements by discussion. These coding decisions were then reviewed by the first and second authors. To calculate interrater reliability, 25\% of the data were subsequently coded by a separate rater familiar with task-based interaction research, reaching $90 \%$ agreement.

Given the modest number of participants and the experimental nature of this research, data from the interactional tasks as well as exit survey data are presented with descriptive statistics in the following sections.

\section{Results}

\section{Proportion of Target-Like Utterances}

The first research question explored the impact of MI on interactional features within SCMC. Data were examined for target-like and nontargetlike utterances, with dyads from both groups producing a total of 1,480 utterances across the pre- and post-tasks (790 pre-task, 690 post-task). Table 2 presents the percentage of target-like utterances in each group across the conditions. The control group had a higher initial accuracy rate than the treatment group. The treatment group showed a $4 \%$ increase in accuracy while the control group decreased 1\%. However, given the small sample size for this exploratory study and the fact that accuracy was not measured over time outside of the pre- and posttests, we limit our reporting here to basic descriptive statistics. Therefore, the proportion of nontarget-like utterances as a space for interactional feedback accounted for $35 \%-42 \%$ of the total interaction data for each group. In other words, more than one third of learners' exchanges provided opportunities for negotiation of meaning and 
interactional feedback. This proportion provided a baseline to compare the occurrence of interactional feedback before and after the intervention.

Table 2

Proportion of Target-like Utterances between Groups across Pre- and Post-Tasks

\begin{tabular}{lcccc}
\hline Group & \multicolumn{2}{c}{ Pre-task } & \multicolumn{2}{c}{ Post-task } \\
\cline { 2 - 5 } & $\%$ & $S D$ & $\%$ & $S D$ \\
\hline Control $(n=10)$ & 65 & .12 & 64 & .17 \\
Treatment $(n=16)$ & 58 & .09 & 62 & .09 \\
\hline
\end{tabular}

\section{Provision of Interactional Feedback}

Table 3 provides a summary of interactional behaviours before and after the intervention between two groups. The control group displayed no difference in the provision of interactional feedback in both pre- and posttests, with no instances of feedback at either time. The treatment group, however, had more recasts and explicit feedback after the intervention. Moreover, at least one instance of each type of interactional feedback was exhibited in the treatment group following the MI intervention.

Table 3

Occurrence of Interactional Feedback between Groups across Pre- and Post-Tasks

\begin{tabular}{|c|c|c|c|c|}
\hline \multirow[b]{2}{*}{$\begin{array}{l}\text { Interactional } \\
\text { Feedback Type }\end{array}$} & \multicolumn{2}{|c|}{ Control $(n=10)$} & \multicolumn{2}{|c|}{ Treatment $(n=16)$} \\
\hline & Pre-task & Post-task & Pre-task & Post-task \\
\hline Clarification request & 0 & 0 & 0 & 1 \\
\hline Confirmation check & 0 & 0 & 0 & 1 \\
\hline Recast & 0 & 0 & 1 & 4 \\
\hline Explicit feedback & 0 & 0 & 0 & 4 \\
\hline Total IF & 0 & 0 & 1 & 10 \\
\hline
\end{tabular}




\section{Modification of Output}

Table 4 shows a slightly positive change in the opportunities for output modification after MI, but the frequency of output modification is minor. Out of 10 occurrences of interactional feedback in the treatment group, there were only four opportunities for output modification and only one instance of modified output was recorded. The control group had no opportunities for or instances of modified output pre- or post-task.

Table 4

Occurrence of Opportunities for Modified Output and Frequency of Output Modification

\begin{tabular}{|c|c|c|c|c|}
\hline \multirow{2}{*}{$\begin{array}{l}\text { Modification of } \\
\text { Output }\end{array}$} & \multicolumn{2}{|c|}{ Control $(n=10)$} & \multicolumn{2}{|c|}{ Treatment $(n=16)$} \\
\hline & Pre-task & Post-task & Pre-task & Post-task \\
\hline Opportunity for MO & 0 & 0 & 1 & 4 \\
\hline MO & 0 & 0 & 0 & 1 \\
\hline
\end{tabular}

\section{Occurrence and Resolution of LRES}

LREs occurred in six out of eight dyads from the treatment group. No LREs were recorded from the control group nor in the treatment group during pretask. Out of 12 LREs, 10 of them were lexical LREs and two were grammatical LREs; $33 \%$ of these LREs were resolved, all of which were lexical LREs. These numbers indicated a marked change in the provision of LREs among those who received metacognitive training. Table 5 illustrates the number and type of LREs produced by the treatment and control groups.

Table 5

Occurrence and Type of LREs between Groups across Pre- and Post-Tasks

\begin{tabular}{llllll}
\hline \multirow{2}{*}{ LRE } & \multicolumn{2}{c}{ Control $(n=10)$} & & \multicolumn{2}{c}{ Treatment $(n=16)$} \\
\cline { 2 - 3 } \cline { 5 - 6 } & Pre-task & Post-task & & Pre-task & Post-task \\
\hline Lexical LREs & 0 & 0 & & 0 & 10 \\
Grammar LREs & 0 & 0 & & 0 & 2 \\
Total LREs & 0 & 0 & & 0 & 12 \\
\hline
\end{tabular}




\section{Learners' Perceptions of the Metacognitive Training}

The second research question addressed learners' perceptions of MI. Analysis of the exit questionnaires indicated that learners largely perceived the metacognitive training as positive. Table 6 provides a descriptive summary of the participants' ratings of several aspects of the training program, with results demonstrating that in general learners found the workshop to be useful. They also reported that they understood the notion of interactional feedback after training, as all learners provided a positive answer (above 4 on the scale). All learners in the treatment group stated that they would like more corrective feedback (CF) training (answers ranging from "somewhat more" to "far more"). The majority of the participants (12/15) "agreed" or "strongly agreed" that they perceived the tasks as useful for their L2 development, thereby highlighting the need for this element in subsequent research. Within the control group, most (10/13) of the learners indicated that they would also like more interactive tasks as part of their regular curriculum, suggesting that most learners perceived the tasks and interactions as beneficial for their learning.

\section{Table 6}

Metacognitive Training Ratings from the Treatment Group $(n=15)$

$-M_{M}$ SD

Perceptions of video activities ( 1 = strongly disagree, 6 = strongly agree)

I felt like the video presentation on corrective feedback was useful for 4.73 0.59 my English development.

I felt like the interactive tasks were useful for my English development.

During the pair activities after the video presentation, I felt like I negotiated more than before.

During the pair activities after the video presentation, I noticed more feedback from my partner than before.

During the pair activities after the video presentation, I noticed more "language", such as new words or expressions.

During the pair activities after the video presentation, I noticed my mistakes more. 
Informative value of workshop ( $1=$ very uninformative, $6=$ very

informative)

How (un)informative did you find the workshop (the presentation and

tasks) to be overall?

\section{Clarity of video ( $1=$ very unclear, $6=$ very clear)}

How (un)clear was the information presented during the video,

Understanding of CF $(1=$ no understanding, $6=$ complete understanding)

How well do you understand what corrective feedback is now?

Future training ( $1=$ less training, $6=$ more training)

The exit questionnaire also included several open-ended questions, which were thematically analyzed to provide additional insight into the learners' perceptions of the training workshop. Learners in the treatment group were asked, "What do you think was the most effective aspect of the workshop (content, organization, practice tasks, etc.)? What do you think needs to be improved?" The majority (10/15) responded that they perceived the practice tasks as the most effective component of the workshop, stating for example: "I think the most effective aspect of the workshop is practice tasks. I can practiced actual situation" (S5, "S" indicates student); "I think the activities by using chatting room with partner is really funny and effective way to communicate with other people" (S2); "I need to use much English as possible as I can, so this tasks were really effective" (S10).

Responses from the open-ended questions also indicated that modality (SCMC) did influence learners' perceptions of their experience. Both treatment and control groups were asked for their opinions about interaction via SCMC, with responses coded as negative or positive. The treatment group had 11 positive and six negative responses (note that several learners provided multiple comments). Positive responses often referenced the additional time afforded by SCMC and/or the ability to view production: "It is so great for us because it can visualize our conversation. We can recognize how we make mistakes unconsciously" (S12), and "it is more comfortable because I and my partner can think about the meaning for more time" (S3). Negative responses included mentions of personal preferences for FTF interaction or difficulty typing: "I prefer practicing English in person" (S4), and "Sometimes difficult because we couldn't see face also, sometimes people use abbreviation words" (S11). The control group had seven positive responses and eight negative 
responses. As in the treatment groups, positive responses often referenced the additional production time afforded by SCMC: "You would have more time to think about your conversation via text chat on the computer, which you can't do on your normally speaking" (S16), and "texting chat is good to make it easy to focus simply" (S23). Negative responses again mentioned issues typing in the L2: "if someone have difficulty in typing, they will waste a lot of time to communicate with others" (S21) and "the different level[s] of typing text in English may be an obstacle to express opinions within limited time" (S17).

\section{Discussion}

Results from this exploratory study suggest a number of benefits for MI for the quality of learners' interactions in an SCMC context. Following MI, learners increased their provision of interactional feedback, which included greater amounts of corrective feedback, the production of more modified output opportunities, and increased LREs. These findings demonstrate that even a single exposure to MI may facilitate improvements in learners' interactional behaviour in computer-mediated environments, aligning with previous research in FTF contexts (Fujii et al., 2016; Fujii \& Mackey, 2009; Sato \& Ballinger, 2012; Sato \& Lyster, 2012). Although previous studies have demonstrated the potential shortcomings of learner-learner interaction (Adams, 2007; García Mayo \& Pica 2000; Fujii \& Mackey 2009; Porter 1986; Toth, 2008), such as low occurrence of or failure to provide feedback, these results offer evidence that training learners in the "hows" and "whys" of interaction (Fujii et al., 2016, p. 80) facilitates increased feedback provision, modified output opportunities, and metalinguistic conversations, thus potentially increasing opportunities for subsequent L2 development. Importantly, the current research extends these positive benefits to the novel context of computer-mediated communication.

Although a direct comparison across modalities is beyond the scope of the current study, important differences between our results and those in FTF contexts were noted. For example, in contrast to previous findings (Fujii et al., 2016), learners in the current research increased their provision of recasts and metalinguistic feedback more than their provision of clarification requests and confirmation checks. Previous FTF studies (Fujii \& Mackey, 2009; Sato \& Lyster, 2007) have demonstrated low amounts of recasts, potentially due to learners' lack of knowledge or attention to form. Although the overall amount of feedback generated by learners was relatively low, the greater number of recasts when compared to clarification requests and confirmation checks found in the current results may be due to the written nature of text chat, which is posited to offer learners additional time for processing and monitoring their production, potentially playing a "significant role in the development of grammatical competence among classroom language 
learners" (Pellettieri, 2000, p. 59). As Lee (2001) pointed out, this visual record of their own production encourages learners to reflect and self-correct, potentially directing their attention to their language output. This may allow learners to "practice and gain control over more cognitively demanding aspects of grammar that otherwise might not be so frequently practiced in classroom oral interaction" (Pellettieri, 2000, p. 82). This is further supported by learners' responses on the exit questionnaires, in which they directly highlighted the benefits of SCMC as providing additional time to think and correct their utterances.

Similar to Zeng's (2017) results, in which half of the participants suggested that "SCMC provided more time for reflection and more opportunities for noticing" (p. 12), the current findings demonstrate learners' awareness of the potential benefits of SCMC (Lai \& Zhao, 2006; Sauro, 2009; Yuksel \& Inan, 2014). These comments from the exit questionnaires lend additional support to the empirical evidence suggesting that learners are afforded greater processing times by text chat. For example, Sauro and Smith (2010) found that learners produced more complex language after monitoring their and their interlocutors' production during online planning time. Indeed, several learners from the treatment group commented directly on the utility of SCMC for self-monitoring for errors and checking corrections: "It is so great for us because it can visualize our conversation. We can recognize how we make mistakes unconsciously" (S15); "I think it's pretty nice. I can remember what we talk about unlike real-world conversation. Also, it makes me double check my grammar" (S7); "I think it's good to improve my English grammar mistakes" (S14). These responses, taken together with the greater provision of interactional feedback for the group that received MI, indicate a potential positive interaction between MI and SCMC. The additional processing time that SCMC provides may facilitate deeper (cognitive) processing and noticing, which in turn may lead to increased interactional feedback.

Regarding the type of feedback provided, within the SCMC context of this research, the greater occurrence of recasts than in previous FTF research may be related to learners' preferences regarding interactional feedback. Akiyama (2017) found that learners participating in SCMC video-based chat chose recasts as the most preferred method of providing and receiving feedback. Learners may have provided recasts in order to reduce face-threatening behaviour (Kötter, 2003), as recasts allowed them to present themselves as friends rather than tutors (Akiyama, 2017). Overall, these findings suggest that the effects of MI may vary across modalities for type of feedback provided.

Learners in the current study also produced a higher proportion of LREs than was found in previous FTF research, providing support for Zeng's (2017) findings. Zeng suggested that the unique features of SCMC offer an environment more supportive of collaborative dialogue than FTF contexts. For example, because a computer-mediated text chat environment 
eliminates the mediating factors of speech rate or volume, which may have a negative effect on learners' comprehension, learners are able to focus on the visual input. Although FTF interaction also includes more information, such as intonation, stress, and social context cues, these features are more likely to affect the communication of meaning rather than the comprehension of form. The lack of paralinguistic and nonverbal information in SCMC, particularly for text chat environments, may promote a focus on L2 form, a finding supported by previous research (Payne \& Whitney, 2002). In other words, the lack of verbal and social cues may more readily facilitate noticing than in a traditional FTF interaction, promoting awareness of gaps in one's interlanguage and encouraging discussion about target features (Blake, 2000; Kelm, 1992). Previous studies also suggest that reviewing chat transcripts may increase learners' noticing of target language features (Lai \& Zhao, 2006; Shekary \& Tahririan, 2006; Yuksel \& Inan, 2014). Importantly, the data from Zeng's (2017) exit questionnaires provide further evidence for these proposed advantages, as learners indicated errors were more "likely to be ignored in F2F than in SCMC" (p. 12).

Overall, MI seems to have raised learners' awareness of how they might become better interactors. This is clearly illustrated in the excerpt below, in which a dyad in the treatment group conceptualizes interactional feedback as a component of the interaction itself.

A: totally $\$ 42$

hammock is $\$ 12$

we can all items we want

we can buy

B: Ok, so we will choose compass (15), fishing pole (12), hammock (12), water filter (15), rain jacket (30), Swiss army knife (15),

A: all items we want. sorry

B: Totally $\$ 99$.

A: oh that's perfect! thank you for calculating

B: Now let us give feedback to each other.

A: ok

B: we can say "we can want all the items", but we can not say we can all the items want."

Please give your feedback on my English. 
A: I think you should have used "How about choosing ?" instead of "we will choose ."

thank you for your feedback

B: Thank you for your feedback, too.

This excerpt demonstrates how these learners came to view feedback as an intentional and integral part of their interaction, providing encouraging evidence for the use of MI. These findings underscore the potential benefits of metacognitive training as this intentional application of feedback demonstrates that learners not only fully understood the concepts presented during the training but also implies that they found them to be useful and applicable to their classroom interactions. This excerpt highlights how learners might apply MI instruction, potentially preparing them to use their knowledge within as well as beyond the classroom.

Finally, this excerpt, as well as responses from the exit questionnaires, suggest a positive relationship between the more socially-oriented affordances of SCMC and metacognitive training. For example, previous research found that introverted learners reported that they felt "freer" to participate in interaction in SCMC contexts (Kern, 1995). The current research adds further support to these findings, with excerpts from the exit questionnaires demonstrating learners' awareness of these affordances of SCMC, with one learner commenting: "It (SCMC) is very nice, I can write a sentence with some thoughts and ask again without shy emotion" (S5, treatment).

\section{Pedagogical Implications}

Findings from the current research demonstrate the benefits of MI for learners' provision of interactional features in a text chat context, providing important pedagogical implications for learners in the L2 classroom. Results indicate that, following MI, learners can and do improve the quality of their peer-peer interactions, thereby increasing the developmental opportunities available to them. As learners become more aware of the importance of interaction for their development and performance, as well as their role in creating and taking advantage of the available interactional opportunities, they may improve both the quantity and quality of their interactions. In other words, MI may help learners to recognize the agency they have in terms of their own learning process, providing them with expanded learning opportunities beyond the classroom (Sato, 1986). By providing MI on negotiation, feedback, and noticing, instructors may be able to offer additional tools for learners to be better interactors in any context in which they are in contact with the target language, thus potentially extending their developmental opportunities beyond the traditional classroom. Furthermore, because the current research 
was conducted using text-based SCMC, findings provide encouraging evidence for the implementation of computer-mediated communication in the classroom. For example, educators may find that by integrating MI and SCMC into their classrooms they are able to provide learners with opportunities for increased participation, production, negotiation, and noticing, thereby further supporting the developmental benefits associated with interaction (e.g., Chun, 1994; Kern, 1995; Lai \& Zhao, 2006; Warschauer, 1996). Although the current findings indicate that learners may demonstrate positive effects in terms of the use and provision of interactional features after a single MI treatment, more instruction and practice may be necessary to promote substantive gains in L2 proficiency.

\section{Limitations}

Although this exploratory research highlights the potential benefits of metacognitive training in SCMC interactions, it is necessary to acknowledge a number of limitations. As this study was exploratory in nature, the sample size is relatively small and from a single academic context, potentially limiting generalizability, and thus results should be interpreted with caution. In order to increase sample size and generalizability, future research should consider multisite research, which offers "greater statistical power and external validity via larger and more diverse participant pools" (Moranski \& Ziegler, in press, p. 1). Learner proficiency may also have played a mediating role on the efficacy of the training. The majority of studies examining MI or modelling have examined intermediate-level learners, thus highlighting the need for further investigation of learners with more advanced language proficiency. Finally, although potential benefits were observed, the current study provided limited exposure to MI. Future research should consider more longitudinal research to investigate how repeated instructional exposure or training of varying durations may affect learners' quality and quantity of interaction.

\section{Conclusion}

This exploratory research provided encouraging evidence for the benefits of MI on learner-learner interaction in SCMC, a previously unexplored context in this area of research. Building upon and extending previous findings (e.g., Fujii et al., 2016), the results of the current study indicate that even a short, one-time metacognitive session on the "hows" and "whys" of interaction (Fujii et al., 2016, p. 80) can lead to increased amounts of interactional features. Learners' perceptions were overall positive, with exit questionnaires indicating learners perceived benefits from the training. In addition, learners' responses demonstrated that they perceived advantages for SCMC as a context supportive of language learning and development. 
Overall, the results of the current study demonstrate how MI or training may help learners improve their opportunities for learning, conferring greater agency on them and increasing their potential for subsequent development.

\section{Acknowledgement}

We would like to thank the participants who made this research possible. We extend our heartfelt gratitude to Dr. Ignasi Gozalo-Salellas for his invaluable contributions to this research. Warmest thanks also to Dr. Alison Mackey and Dr. Akiko Fujii for their research in this area, which served as the foundation upon which we were able to build. In addition, we are grateful to the editors of this special issue, Dr. Eva Kartchava and Dr. Antonella Valeo, for their patience, support, and guidance, and to the reviewers for their insightful comments and helpful suggestions. Any remaining errors are ours alone.

\section{The Authors}

Nicole Ziegler (University of Hawai'i at Mānoa) focuses on instructed second language acquisition (ISLA), including mixed method research in interaction, task-based language teaching (TBLT), and computer-assisted language learning (CALL). Her current research explores the role of metacognitive instruction in interaction, as well as task-based approaches for Maritime English.

Kara Moranski (University of Cincinnati) uses her training in both applied linguistics and educational statistics to conduct curricular research, investigating what is working in contemporary language classes in $\mathrm{K}-12$ and postsecondary settings. Her recent work has focused on flipped learning models and metacognitive instruction to promote peer interaction.

George Smith (University of Hawai'i at Mānoa) is a PhD candidate in the Department of Second Language Studies. His interests include second language listening and speaking, vocabulary, corpus linguistics, and TBLT. He is particularly interested in interfacing these interests to support learning in English for academic purposes (EAP) programs.

Huy Phung (University of Hawai'i at Mānoa) is currently a PhD candidate in the Department of Second Language Studies. His research focuses on how interaction facilitates (second) language acquisition and development, and how learners can be taught to maximize their learning opportunities in task-based interaction.

\section{References}

Adams, R. (2007). Do second language learners benefit from interacting with each other? In A. Mackey (Ed.), Conversational interaction in second language acquisition (pp. 29-52). Oxford University Press.

Adams, R., Nuevo, A. M., \& Egi, T. (2011). Explicit and implicit feedback, modified output, and SLA: Does explicit and implicit feedback promote learning and learner-learner interactions? The Modern Language Journal, 95(s1), 42-63. https://doi.org/10.1111/j.1540-4781.2011.01242.x

Ahmadian, M., \& Tajabadi, A. (2020). Collaborative dialogue: Opportunities and challenges in vocabulary acquisition and retention of threshold EFL learners, International Review of Applied Linguistics in Language Teaching, 58(2), 133-160. https://doi.org/10.1515/iral-2017-0175

Akiyama, Y. (2017). Learner beliefs and corrective feedback in telecollaboration: A longitudinal investigation. System, 64, 58-73.

Baralt, M. (2010). Task complexity, the Cognition Hypothesis, and interaction in CMC and FTF environments. [Unpublished doctoral dissertation]. Georgetown University.

Blake, R. (2000). Computer-mediated communication: A window on L2 Spanish interlanguage. Language Learning \& Technology, 4(1), 111-125. 
Chun, D. M. (1994). Using computer networking to facilitate the acquisition of interactive competence. System, 22(1), 17-31.

Dao, P. (2020). Effect of interaction strategy instruction on learner engagement in peer interaction. System, 102244. https://doi.org/10.1016/j.system.2020.102244

Foster, P. (1998). A classroom perspective on the negotiation of meaning. Applied Linguistics, 19(1), 1-23. https://doi.org/10.1093/applin/19.1.1

Foster, P., \& Ohta, A. S. (2005). Negotiation for meaning and peer assistance in second language classrooms. Applied Linguistics, 26(3), 402-430. https://doi.org/10.1093/applin/ami014

Fujii, A., \& Mackey, A. (2009). Training learners to be more effective interactors. The 3rd Biennial Conference on Task-Based Language Teaching, Lancaster, UK.

Fujii, A., Ziegler, N., \& Mackey, A. (2016). Peer interaction and metacognitive instruction in the EFL classroom. In M. Sato \& S. Ballinger (Eds.), Peer interaction and second language learning: Pedagogical potential and research agenda (Vol. 45, pp. 63-90). John Benjamins Publishing Company. https://doi.org/10.1075/lllt.45.10gar

García Mayo, M. del P., \& Pica, T. (2000). Interaction among proficient learners: Are input, feedback and output needs addressed in a foreign language context? Studia Linguistica, 54(2), 272-279. https://doi.org/10.1111/1467-9582.00066

Gurzynski-Weiss, L., \& Baralt, M. (2015). Does type of modified output correspond to learner noticing of feedback? A closer look in face-to-face and computer-mediated task-based interaction. Applied Psycholinguistics, 36(6), 1393-1420.

Keck, C. M., Iberri-Shea, G., Tracy-Ventura, N., \& Wa-Mbaleka, S. (2006). Investigating the empirical link between task-based interaction and acquisition: A meta-analysis. In J. M. Norris \& L. Ortega (Eds.), Language learning \& language teaching (Vol. 13, pp. 91-131). John Benjamins Publishing Company. https://doi.org/10.1075/1llt.13.08kec

Kelm, O. R. (1992). The use of synchronous computer networks in second language instruction: A preliminary report. Foreign Language Annals, 25(5), 441-454.

Kern, R. G. (1995). Restructuring classroom interaction with networked computers: Effects on quantity and characteristics of language production. The Modern Language Journal, 79(4), 457-476. https://doi.org/10.1111/j.1540-4781.1995.tb05445.x

Kim, Y., \& McDonough, K. (2008). The effect of interlocutor proficiency on the collaborative dialogue between Korean as a second language learners. Language Teaching Research, 12(2), 211-234. https://doi.org/10.1177/1362168807086288

Kötter, M. (2003). Negotiation of meaning and codeswitching in online tandems. Language Learning \& Technology, 7(2), 145-172.

Lai, C., \& Zhao, Y. (2006). Noticing and text-based chat. Language Learning \& Technology, 10(3), 102-120.

Lee, L. (2001). Online interaction: Negotiation of meaning and strategies used among learners of Spanish. ReCALL, 13, 232-244.

Lee, L. (2009). Exploring native and nonnative interactive discourse in text-based chat beyond classroom settings. In L. B. Abraham \& L. Williams (Eds.), Language Learning \& Language Teaching (Vol. 25, pp. 127-150). John Benjamins Publishing Company. https://doi.org/10.1075/ 11lt.25.10lee

Leow, R. P. (2015). Explicit learning in the L2 classroom: A student-centered approach. Routledge.

Leow R. P. (2018). Explicit learning and depth of processing in the instructed setting: Theory, research, and practice. Studies in English Education, 23, 769-801. http://dx.doi.org/10.22275/ SEE.23.4.01

Long, M. (1983). Linguistic and conversational adjustments to non-native speakers. Studies in Second Language Acquisition, 5, 177-193.

Long, M. H. (1996). The role of the linguistic environment in second language acquisition. In W. C. Ritchie \& T. K. Bhatia (Eds.), Handbook of second language acquisition (pp. 413-468). Academic Press. https://doi.org/10.1016/B978-012589042-7/50015-3

Loschky, L., \& Bley-Vronman, R. (1990). Grammar and task-based methodology. In G. Crookes 
\& S. M. Gass (Eds.), Tasks and language learning: Integrating theory and practice (Vol. 93, p. 45). Multilingual Matters.

Lyster, R., \& Ranta, L. (1997). Corrective feedback and learner uptake: Negotiation of form in communicative classrooms. Studies in Second Language Acquisition, 19(1)37-66.

Mackey, A. (2012). Input, interaction and corrective feedback in L2 classrooms. Oxford University Press.

Mackey, A., \& Goo, J. (2007). Interaction research in SLA: A meta-analysis and research synthesis. In A. Mackey (Ed.), Conversational interaction in second language acquisition: A series of empirical studies (pp. 407-453). Oxford University Press.

Mackey, A., \& Oliver, R. (2002). Interactional feedback and children's L2 development. System, 30(4), 459-477.

Mackey, A., Oliver, R., \& Leeman, J. (2003). Interactional input and the incorporation of feedback: An exploration of NS-NNS and NNS-NNS adult and child dyads. Language Learning, 53(1), 35-66. https://doi.org/10.1111/1467-9922.00210

McGuire, S. Y. (2015). Teach students how to learn: Strategies you can incorporate into any course to improve student metacognition, study skills, and motivation. Stylus Publishing, LLC.

Meunier, L. E. (1998). Personality and motivational factors in computer-mediated foreign language communication (CMFLC). In J. Muyskens (Ed.), New ways of learning and teaching: Focus on technology and foreign language education, (pp. 145-197). Boston: Heinle \& Heinle.

Moranski, K., \& Henery, A. (2017). Helping learners to orient to the inverted or flipped language classroom: Mediation via informational video. Foreign Language Annals, 50(2), 285-305. https://doi.org/10.1111/flan.12262

Moranski, K., \& Ziegler, N. (in press). A case for multisite research in SLA: Challenges, risks, and rewards. Language Learning.

Oliver, R., \& Mackey, A. (2003). Interactional context and feedback in child ESL classrooms. The Modern Language Journal, 87(4), 519-533.

Payant, C., \& Kim, Y. (2019). Impact of task modality on collaborative dialogue among plurilingual learners: A classroom-based study. International Journal of Bilingual Education and Bilingualism, 22(5), 614-627. https://doi.org/10.1080/13670050.2017.1292999

Payne, J. S., \& Whitney, P. J. (2002). Developing L2 oral proficiency through synchronous CMC: Output, working memory, and interlanguage development. CALICO Journal, 20(1), 26.

Pellettieri, J. (2000). Negotiation in cyberspace: The role of chatting in the development of grammatical competence. In M. Warschauer \& R. Kern (Eds.), Network-based language teaching (pp. 59-86). Cambridge University Press. https://doi.org/10.1017/CBO9781139524735.006

Philp, J., Walter, S., \& Basturkmen, H. (2010). Peer interaction in the foreign language classroom: What factors foster a focus on form? Language Awareness, 19(4), 261-279. https://doi.org/10. 1080/09658416.2010.516831

Pica, T. (1994). Research on negotiation: What does it reveal about second-language learning conditions, processes, and outcomes? Language Learning, 44(3), 493-527. https://doi. org/10.1111/j.1467-1770.1994.tb01115.x

Pica, T., \& Doughty, C. J. (1985). Input and interaction in the communicative language classroom: A comparison of teacher-fronted and group activities. In S. M. Gass \& C. Madden (Eds.), Input in second language acquisition (pp. 115-132). Newbury House.

Pica, T., Kanagy, R., \& Falodun, J. (1993). Choosing and using communication tasks for second language instruction. In G. Crookes \& S. M. Gass (Eds.), Tasks and language learning: Integrating theory and practice (pp. 9-34). Multilingual Matters.

Plonsky, L., \& Ziegler, N. (2016). The CALL-SLA interface: Insights from a second-order synthesis. Language Learning \& Technology, 20(202), 17-37.

Porter, P. (1986). How learners talk to each other: Input and interaction in task-centered discussions. In R. R. Day (Ed.), Talking to learn: Conversation in second language acquisition (pp. 200-222). Rowley, MA: Newbury.

Salaberry, M. R. (2000). L2 morphosyntactic development in text-based computer-mediated communication. Computer Assisted Language Learning, 13(1), 5-27. 
Sato, C. J. (1986). Conversation and interlanguage development: Rethinking the connection. In R. R. Day (Ed.), Talking to learn: Conversation in second language acquisition (pp. 5-22), Rowley, MA: Newbury House.

Sato, M. (2013). Beliefs about peer interaction and peer corrective feedback: Efficacy of classroom intervention. The Modern Language Journal, 97(3), 611-633. https://doi.org/10.1111/j.15404781.2013.12035.x

Sato, M., \& Ballinger, S. (2012). Raising language awareness in peer interaction: a cross-context, cross-methodology examination. Language Awareness, 21(1-2), 157-179.

Sato, M., \& Loewen, S. (2018). Metacognitive instruction enhances the effectiveness of corrective feedback: Variable effects of feedback types and linguistic targets. Language Learning, 68(2), 507-545. https://doi.org/10.1111/lang.12283

Sato, M., \& Lyster, R. (2007). Modified output of Japanese EFL learners: Variable effects of interlocutor versus feedback type. In A. Mackey (Ed.), Conversational interaction in second language acquisition (pp. 123-142). Oxford University Press.

Sato, M., \& Lyster, R. (2012). Peer interaction and corrective feedback for accuracy and fluency development. Studies in Second Language Acquisition, 34(4), 591-626. https://doi.org/10.1017/ S0272263112000356

Sauro, S. (2009). Computer-mediated corrective feedback and the development of L2 grammar. Language Learning \& Technology, 13(1), 96-120.

Sauro, S., \& Smith, B. (2010). Investigating L2 performance in text chat. Applied Linguistics, 31(4), 554-577. https://doi.org/10.1093/applin/amq007

Shekary, M., \& Tahririan, M. H. (2006). Negotiation of meaning and noticing in text-based online chat. The Modern Language Journal, 90(4), 557-573. https://doi.org/10.1111/j.15404781.2006.00504.x

Sippel, L. (2019). The impact of peer corrective feedback on vocabulary development. Foreign Language Annals, flan.12416. https://doi.org/10.1111/flan.12416

Smith, B. (2004). Computer-mediated negotiated interaction and lexical acquisition. Studies in Second Language Acquisition, 26(3). https://doi.org/10.1017/S027226310426301X

Smith, B. (2005). The relationship between negotiated interaction, learner uptake, and lexical acquisition in task-based computer-mediated communication. TESOL Quarterly, 39(1), 33. https://doi.org/10.2307/3588451

Smith, G., \& Ziegler, N. (2016, September). Exploring the effects of meta-cognitive instruction and peer interaction on learners' L2 pronunciation awareness. Second Language Research Forum, New York, NY.

Swain, M. (1985). Communicative competence: Some roles of comprehensible input and comprehensible output in its development. In S. M. Gass \& C. Madden (Eds.), Input in second language acquisition (pp. 165-179). Newbury House.

Swain, M. (1995). Three functions of output in second language learning. In G. Cook \& B. Seidlhofer (Eds.), Principle and practice in applied linguistics: Studies in honour of HG Widdowson (pp. 125-144). Oxford University Press.

Swain, M. (1998). Focus on form through conscious reflection. In C. Doughty \& J. Williams (Eds.), Focus on form in classroom second language acquisition (pp. 64-81). Cambridge University Press.

Swain, M. (2005). The output hypothesis: Theory and research. In E. Hinkel (Ed.), Handbook of research in second language teaching and learning (pp. 495-508). Routledge.

Swain, M., \& Lapkin, S. (1995). Problems in output and the cognitive processes they generate: A step towards second language learning. Applied Linguistics, 16(3), 371-391.

Swain, M., \& Lapkin, S. (1998). Interaction and second language learning: Two adolescent French immersion students working together. The Modern Language Journal, 82(3), 320-337. https:// doi.org/10.1111/j.1540-4781.1998.tb01209.x

Toth, P. D. (2008). Teacher- and learner-led discourse in task-based grammar instruction: Providing procedural assistance for L2 morphosyntactic development. Language Learning, 58(2), 237-283. https://doi.org/10.1111/j.1467-9922.2008.00441.x 
Toth, P. D., Wagner, E., \& Moranski, K. (2013). 'Co-constructing' explicit L2 knowledge with high school Spanish learners through guided induction. Applied Linguistics, 34(3), 279-303.

Warschauer, M. (1996). Comparing face-to-face and electronic discussion in the second language classroom. CALICO Journal, 13(2), 7-26.

Yanguas, I. (2012). Task-based oral computer-mediated communication and L2 vocabulary acquisition. CALICO Journal, 29(3), 507-531. https://doi.org/10.11139/cj.29.3.507-531

Yuksel, D., \& Inan, B. (2014). The effects of communication mode on negotiation of meaning and its noticing. ReCALL, 26(3), 333-354. https://doi.org/10.1017/S0958344014000147

Zeng, G. (2017). Collaborative dialogue in synchronous computer-mediated communication and face-to-face communication. ReCALL, 29(3), 257-275. https://doi.org/10.1017/ S0958344017000118

Ziegler, N. (2016). Synchronous computer-mediated communication and interaction. Studies in Second Language Acquisition, 38(3), 553-586. https://doi.org/10.1017/S027226311500025X

Ziegler, N., \& Moranski, K. (2018, March). A cross-linguistic approach for metacognitive instruction on interactional feedback in the L2 classroom: Findings from a mixed methods design. American Association for Applied Linguistics, Chicago, IL. 